\title{
Network Intensity: Assessing the Strategic Value of Installed Base
}

\author{
David P. Mclntyre \\ Providence College • Providence, Rl
}

\section{Abstract}

The purpose of this research is to explore variation in the influence of network effects across competitive settings. Specifically, this study tests for significant differences in the impact of a product's installed base on its growth in an industry influenced by network effects, application software. Variation in size-on-growth effects across industry segments is conjectured to be a function of the network intensity, or degree of consumer interdependence, of the segments. The results illustrate significant variation in the magnitude of size-on-growth effects across segments, consistent with the notion of network intensity. Implications for strategy in hightechnology settings are discussed.

\section{Introduction}

Network effects broadly refer to conditions in which consumer demand is interdependent, i.e., where consumers prefer to use products or technologies that many other consumers also use (Katz \& Shapiro, 1986; Rohlfs, 1974). Industries influenced by network effects offer a compelling context for the study of strategy and innovation management. In these "network industries," a single firm can enjoy robust growth and industry dominance via forces of positive feedback that tend to push the market toward the adoption of a single product or product design (David, 1985; Arthur, 1989). When consumers value a large cohort of fellow adopters for a given product, extant theory suggests that the firm with the largest installed base (i.e., current users of the product) should be optimally positioned to win the battle for market dominance.

Despite an increasing number of empirical advances regarding network effects (e.g. Eisenmann, 2007; Hill, 1997; Majumdar \& Venkatraman 1998; Schilling, 2002), studies of the direct impact of installed base size on firm growth are largely absent from the strategy literature, with few exceptions (Chacko \& Mitchell, 1998; Shankar and Bayus, 2003). Furthermore, while the existence of network effects has been well established, the extent to which they manifest heterogeneously across competitive contexts remains unclear. Extant theory tends to focus on the presence, rather than the magnitude, of network effects in various high-technology settings. 
As a preliminary step toward understanding variation in the impact of network effects, this research examines the influence of installed base size on growth in the application software industry. Specifically, variation in size-on-growth effects across segments of the industry is examined, and the concept of network intensity is described as a rationale for such variation. The impact of installed base size on growth is found to vary significantly across segments, consistent with the notion of network intensity and the characteristics of the individual segments. This finding has important implications for firm strategy and the management of innovation, as the strength of network intensity may significantly impact the optimal timing of market entry and generational product releases.

\section{Theoretical Background}

\section{Network Industries: Characteristics and Prevalence}

Network effects occur when consumers value a given product contingent upon the number of people who are already using it (Katz \& Shapiro, 1986; Farrell $\&$ Saloner, 1986). Network effects can be seen in basic technologies such as telephones and fax machines, which have very little value to a consumer in the absence of other users of the product. For such products, as well as more modern examples such as online auctions, consumers tend to value a network of other users, as this network is essential to derive value from the product.

Network effects are thought to be an important strategic aspect of many hightechnology industries (Arthur, 1996; Eisenmann, 2007; McIntyre \& Subramaniam, 2009; Tanrivierdi \& Lee, 2008). In such settings, competitive outcomes are heavily influenced by positive feedback to leading products, whereby each new user of a product increases the likelihood of future users adopting the product. For example, as a social networking site such as Facebook increases its user base, it becomes increasingly attractive to future users who could interact with a larger number of friends, family members, or other users of the site. When such positive feedback accrues to a leading firm and its technology, there is a tendency for the "strong to grow stronger and the weak to grow weaker" (Shapiro, 1999). Thus, firms with an early foothold in the market tend to increase their lead, while those who are unable to attract a critical mass of adopters tend to be competed out of the marketplace. Once a leading product emerges, positive feedback tends to push a single product, and its sponsoring firm, toward dominance of the focal market (Besen \& Farrell, 1994). 


\section{The Influence of Installed Base Size on Growth}

While a broad literature in strategy and industrial organization has found mixed effects in the relationship between measures of organizational size and growth (e.g., Penrose, 1955; Hymer \& Pashigian, 1962; Evans, 1987; Hall, 1987), these studies focus primarily on manufacturing industries, in which the benefits of network effects are largely absent (Arthur, 1996). Conversely, in network industries, the size of a product's installed base is thought to be a primary determinant of its growth. Specifically, a large installed base confers at least three types of benefits to potential adopters: direct network benefits, reduced uncertainty, and indirect effects benefits via availability of complementary products.

First, direct network benefits are present when the value of a product is largely a function of the number of other individuals or firms using it (Chacko \& Mitchell, 1998). Examples include telecommunications networks and certain types of computer software, wherein network participants interact frequently, and thus value compatibility with a large number of other participants.

Second, when product adoption requires some degree of learning investments by consumers, uncertainty about the returns to these investments can be problematic. A large installed base acts as a signal that a given product exhibits some degree of long-term viability, thereby reducing uncertainty and assuring adopters that investments in learning will be beneficial (Brynjolffson \& Kemerer, 1996).

Third, a large installed base is thought to attract producers of complementary goods and services to the focal product (Clements \& Ohashi, 2005; Stremersch et al., 2007; Venkatraman \& Lee, 2004). For example, software vendors must decide which operating system platforms to target when developing new applications. The platform with the larger installed base offers a larger potential pool of adopters for the application, over which the vendor may be able to exploit economies of scale in production (Chacko \& Mitchell, 1998).

\section{Variation in Size-on-Growth Effects: The Role of Network Intensity}

Much of the empirical literature on network effects focuses on technologyoriented industries, such as software or Internet commerce (e.g., Brynjolfsson \& Kemerer, 1996; Schilling, 1998; Eisenmann, 2007; Tanrivierdi \& Lee, 2008). Yet from a strategy perspective, the presence or strength of network effects in these select industries may be less informative than the relative influence of network effects across the competitive landscape. For example, in social networking Web sites, we expect that installed base size plays a very strong role in driving installed base 
growth, as such sites have almost no residual value in the absence of a network of fellow adopters. ${ }^{1}$ However, other products, such as video game consoles, have a great deal of value to individual users in the absence of network interaction. For both social networking and video games, consumers derive some value from interacting with a network, yet in the case of video games, the proportion of total value derived from network membership is likely lower than in online auctions.

Figure 1 presents a very basic illustration of this notion, with the light region representing the proportion of a product's value that is dependent on network size, and the shaded region representing the proportion of network-independent value. If the total value of a product is conceptualized as the sum of its network value and network-independent value, then one might expect video game consoles to lie near point $\mathrm{A}$, as consumers can derive value from simply using the console, but also from the ability to exchange or play online games with fellow users. In contrast, social networking sites would lie closer to point $\mathrm{B}$, as the brunt of their value comes from the consumer's ability to interact with the largest possible network of users.

Note that Figure 1 makes a critical assumption underlying the nature of network effects, in that it portrays the total value of any product as normalized across a broad spectrum of products. In other words, a vast array of consumer goods, from those with very little network value (e.g., clothing, appliances) to those with very high network value (e.g., computer operating systems, online auctions), are assumed to have some overall value to an adopter of the product. This overall value is depicted on the vertical axis as a function of both network and network-independent value. Theoretically, this standardization of product value allows for a more robust illustration of network intensity as a continuum, along which virtually any product could characterized by the relative influence of network membership for a product. Thus, Figure 1 presents a basic conceptual framework for network intensity; specific empirical techniques for applying such standardized measures across products are beyond the scope of this article.

\section{Figure 1}

\section{Basic Illustration of Network Intensity}

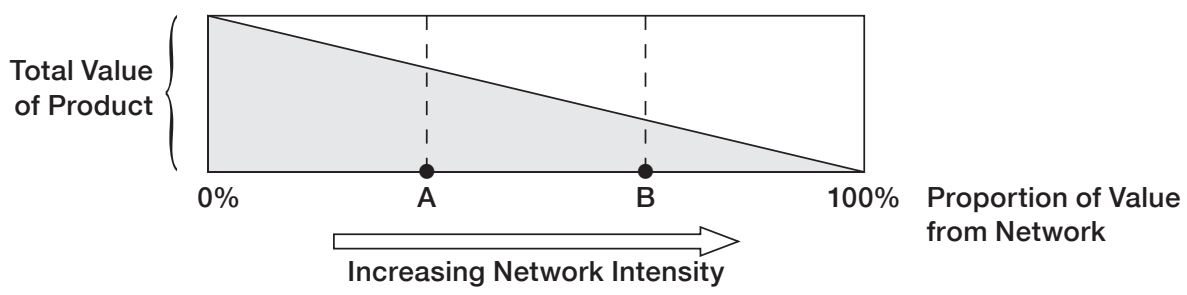


For this research, network intensity is conceptualized as the proportion of total value that consumers derive from network interaction for a given product, ceteris paribus. ${ }^{2}$ This notion, that network effects manifest heterogeneously for different products, is not an entirely novel one. For example, previous literature has noted the implications of asymmetric network effects at the industry (Lin \& Kulatilaka, 2006) and firm level (Shankar \& Bayus, 2003), as well as the drawbacks of using gross installed base size to approximate network value (Suarez, 2005). However, empirical tests of this phenomenon are largely absent from the literature, and a comprehensive framework for assessing the competitive influence of network intensity remains elusive.

Observing significant variation in size-on-growth effects across segments of a network industry would provide preliminary evidence that network intensity is heterogeneous across these industry segments. Thus:

Hypothesis 1: In a network industry, the effect of installed base size on growth will vary significantly across segments.

A stronger form of this hypothesis is that size-on-growth effects will vary in accordance with the network intensity of the product, i.e., the greater the network intensity in a given setting, the stronger the influence of installed base size on growth. While no quantifiable measures of network intensity are evident in the literature, certain product characteristics are indicative of greater network intensity. For example, the word processing and spreadsheet segments of the application software industry have frequently been used in empirical tests of network effects, as compatibility with a broad base of other users is critical (e.g., Gandal, 1995; Brynjolfsson \& Kemerer, 1996; Liebowitz \& Margolis, 1999). In contrast, applications such as desktop publishing and CAD may be less network-intensive, as their outputs tend to have value largely to a single user, or to a relatively small cohort around that focal user (Astebro, 2002).

Thus, the proportion of value that consumers derive from installed base size varies as consumers increasingly desire network interaction for a product, or as total network size is more important than interaction with smaller, more tightly connected groups of consumers (Suarez, 2005). In sum, network intensity moderates the relationship between a product line's installed base size and its growth in future periods - the stronger the network intensity, the more positive the effect of installed base size on growth.

A stronger form of Hypothesis 1, contextualized to the application software industry is proposed: 
Hypothesis 2: The effect of installed base size on growth will be more positive in high network-intensity segments (i.e., word processing and spreadsheets) than in other segments.

\section{$\overline{\text { Data and Methods }}$}

For this research, data were gathered on a sample of software releases in four segments of packaged application software (NAICS 51120) from 1986-1998 - word processing, spreadsheet, desktop publishing, and computer-aided design (CAD) segments. Application software is thought to exhibit many of the characteristics of network dynamics (e.g., Brynjolffsson \& Kemerer, 1996; Chacko \& Mitchell, 1998; Liebowitz \& Margolis, 1999), and this time frame represented a period of significant growth in the industry. Because these four segments of application software exhibited focal products with unique attributes, as well as significantly different competitors, they were thought to be an ideal focus for the explorative study of network intensity dynamics.

The raw sample for the study included 247 product-years in the word processing, spreadsheet, desktop publishing, and CAD segments. These included both leading products, such as Microsoft Word and Aldus PageMaker (in word processing and desktop publishing, respectively), and lesser-known products such as DisplayWrite and FrameMaker. As different operating systems may have influenced growth patterns, the sample was limited to software that was compatible with the dominant platforms, the DOS/Windows operating systems. This constraint, along with a lack of sufficient installed base data for some observations resulted in a final sample of 125 product-years encompassing 21 product lines.

The time frame of the sample offered a chance to explore emerging products influenced by network effects, and a period of substantial growth in all four segments. For example, the total units shipped in the word processing segment doubled roughly every two years throughout this time period. Yearly data on market share, sales, shipments, price and revenue were gathered from a dataset based on reports provided by IDC (International Data Corporation) and DataQuest, leading providers of market research in software and other information technologies. Information on product release dates, corporate parents, and general background were gathered through archival searches of software trade journals and periodicals, including InfoWorld, PC World, PC Magazine, PC Week and Byte. 


\section{Measures}

\section{Dependent Variable: Change in Installed Base}

The dependent variable of interest is the change in a product line's installed base over a one-year period. Consistent with Chacko and Mitchell's (1998) study of network dynamics, this study holds that lagged cumulative unit sales over a twoyear period provide a reasonable approximation of a product's installed base. Thus, change in installed base is measured as the difference between the natural logs of the product's installed base at times $t_{+1}$ and $t_{0}$, i.e., the size of the base in the following year less the size of the current base.

\section{Independent Variables}

The first independent variable of interest is a product's existing installed base in a given year. As noted previously, installed base size was measured as lagged cumulative unit sales over a two-year period. A quadratic term on installed base was incorporated to gauge curvilinear and critical mass effects of installed base. Such effects tend to be indicative of "critical mass" in network industries, where firms are competed out of the market unless they achieve a certain level of installed base, after which they tend to enjoy stronger growth due to the benefits of network effects.

The influence of network intensity was captured in two ways: first, interactive terms between segment dummy variables and installed base were developed, to gauge significant differences in each segment from the mean in size-on-growth effect across other segments. Second, a network intensity dummy variable was coded, whereby high-network intensity (i.e., word-processing and spreadsheets) segments were coded " 1 " and other segments were coded " 0 ." This dummy was also interacted with installed base to test the stronger-form hypothesis that size-on-growth effects vary in a manner consistent with the network intensity of a segment.

\section{Control Variables}

\section{Segment Characteristics}

Concentration. The degree of segment concentration may have a significant influence on innovativeness, average profitability, and firm growth potential (Stigler, 1964; Porter 1980). One measure of concentration was included in the model, the Herfindahl-Hirschman Index (HHI), which indicates the sum of the squared market shares of competitors, to control for concentration effects at the segment level. 
Platform. A dummy variable was included indicating the operating system platform for which the software was designed - DOS or Windows. This variable was included to ensure that growth dynamics are not platform-dependent or unduly influenced by broader patterns of platform use.

\section{Product Characteristics}

Price. The retail price of a network product has been described as an important factor in network competition (Shapiro \& Varian, 1999). Yet if price or product discounts fully account for installed base growth, then simple firm economies of scale may explain the brunt of growth patterns in these settings. Thus, the price of the product in a given year was included in the model.

Generational Innovation. A generational product innovation is a substantial advance in the technical performance of a product (Lawless \& Anderson, 1996). Conversely, incremental product innovation focuses on the reinforcement of existing product designs, leaving fundamental aspects of the product unchanged (Henderson $\&$ Clark, 1990). For each product-year, a variable indicating the generational nature of the product was included. A product was coded 1 if its primary version in a given year represented a whole number (2, 2.0 etc.), and 0 if the primary version contained one or more decimal points $(5.1,5.01$, etc.)

\section{Firm-level Characteristic}

Multi-segment firm. Firms competing in multiple segments of an industry may have a dual advantage with regard to performance metrics such as growth. First, firms that compete in related segments are thought to possess certain managerial advantages because of their relatedness (Rumelt, 1973; Bettis 1981). Second, these firms may have greater capabilities to leverage related competitive knowledge across multiple segments (Henderson \& Cockburn, 1996 ; Tanrivierdi and Venkatraman, 2004). As such, firms which produced products in more than one segment of the sample (Microsoft and IBM, for example) were assigned a "1," others a "0" for this variable.

\section{Summary Model}

The baseline model used to test the effect of installed base size on growth, and significant variation in these effects due to network intensity, is as follows: 
$\left(\ln\right.$ Installed Base ${ }_{t+1}-\ln$ Installed Base $\left.{ }_{t}\right)=\beta_{0}+\beta_{l}(\ln$ Installed Base $)$ $+\beta_{2}(\text { lnInstalled Base })^{2}+\beta_{3}$ (Price $)+\beta_{4}($ Multi-segment Firm $)+$ $\beta_{5}($ Concentration $)+\beta_{6}($ Platform $)+\beta_{7}($ Generational Innovation $)+$ $\beta_{8}\left(\right.$ Network Intensity $* \ln$ Installed Base $\left.{ }_{t}\right)$

\section{$\overline{\text { Results }}$}

Descriptive statistics and correlations for the sample are shown in Table 1. Note that installed base size has a negative correlation with growth $(r=-0.16)$, which is consistent with previous empirical findings of a negative linear relationship but positive curvilinear relationship between size and growth in network industries. Firms competing in multiple segments tend to be associated with larger installed bases in those segments $(r=0.38)$, but also lower prices $(r=-0.07)$, which is somewhat surprising given the concerns over pricing and antitrust in network industries (Liebowitz \& Margolis, 1999).

Recall that the hypotheses relate to variation in the influence of installed base size in driving growth in the application software industry. Results of the regression analyses (product-line fixed effects models) are shown in Table 2. Several specific aspects of these analyses merit further discussion. First, the negative linear and positive quadratic terms on installed base in the nested models suggest that installed base size has a generally negative impact on growth, which becomes more positive as installed base size increases (the quadratic term is positive in all models, and significant at $\mathrm{p}<.05$ in two of the models). This finding is again consistent with the notion of "critical mass" effects in network industries (Chacko \& Mitchell, 1998).

Hypothesis 1 holds that significant variation will be observed among segments in the focal industry, packaged application software. Consistent with this hypothesis, the interaction terms between segment dummies for spreadsheets, desktop publishing, and CAD are significant (Model 3), indicating that size-on growth effects are significantly different for each segment relative to the mean effect of the other segments. CAD and desktop publishing appear to have lower baseline size-ongrowth effects relative to the other segments $(\beta=-0.64, \beta=-0.44)$, while spreadsheets appear to be exhibit significantly stronger effects than other segments $(\beta=$ 0.41 ). The word processing segment also appears to have significantly more positive size-on-growth effects $(\beta=0.06)$, though only marginally so $(\mathrm{p}<.10)$. Thus, Hypothesis 1 is generally supported, in that influence of installed base size on growth in each segment varies significantly from the mean effect of the other segments. 
Table 1

Descriptive statistics for key variables $(n=126)$

\begin{tabular}{lrrrrrrrr}
\hline & Mean & S.D. & $\mathbf{1}$ & $\mathbf{2}$ & $\mathbf{3}$ & $\mathbf{4}$ & $\mathbf{5}$ & $\mathbf{6}$ \\
\hline 1. Growth & 0.17 & 1.13 & & & & & & \\
2. Installed Base & 14.23 & 1.90 & -0.16 & & & & & \\
3. Price & 146.59 & 98.39 & -0.01 & -0.32 & & & & \\
4. Generational & 0.50 & 0.49 & 0.03 & 0.23 & -0.08 & & & \\
$\quad$ innovation & & & & & & & & \\
5. Platform & 0.70 & 0.46 & 0.06 & 0.44 & -0.12 & -0.03 & & \\
6. Multi-segment firm & 0.39 & 0.17 & -0.03 & 0.38 & -0.07 & 0.14 & 0.01 & \\
7. Concentration & 0.68 & 0.47 & 0.07 & 0.52 & -0.18 & 0.09 & 0.61 & 0.10 \\
\hline
\end{tabular}

Hypothesis 2 tests whether the segments that were conjectured to exhibit higher network intensity do indeed exhibit stronger size-on-growth effects. The primary variable of interest for this hypothesis is the interaction term between the network intensity dummy variable and installed base (coefficient $\beta_{8}$ in the model described previously, or "Network intensity*Installed base" in Table 2). Given the positive and significant interaction term, this hypothesis is supported in both the baseline model (Model 2) and the full model with controls (Model 4). Thus, segments which have been hypothesized to exhibit stronger network effects - word processing and spreadsheets — do indeed appear to exhibit stronger size-on-growth effects than other segments. 
Table 2

Regression results (DV $=$ Installed base growth)

\begin{tabular}{|c|c|c|c|c|}
\hline & 1 & 2 & 3 & 4 \\
\hline Concentration $(\mathrm{HHI})$ & & & $\begin{array}{c}-0.94^{*} \\
(0.54)\end{array}$ & $\begin{array}{l}-0.16 \\
(0.63)\end{array}$ \\
\hline Price & & & $\begin{array}{c}0.58 \\
(0.90)\end{array}$ & $\begin{array}{c}0.17 \\
(0.99)\end{array}$ \\
\hline Multi-segment firm & & & $\begin{array}{c}0.77 \\
(0.57)\end{array}$ & $\begin{array}{c}0.22 \\
(0.54)\end{array}$ \\
\hline Generational product innovation & & & $\begin{array}{c}0.13 \\
(0.15)\end{array}$ & $\begin{array}{c}0.10 \\
(0.14)\end{array}$ \\
\hline Platform & & & $\begin{array}{c}0.18 \\
(0.25)\end{array}$ & $\begin{array}{c}0.02 \\
(0.14)\end{array}$ \\
\hline (In) Installed base & $\begin{array}{l}-3.14^{\star \star \star} \\
(0.64)\end{array}$ & $\begin{array}{l}-1.34^{*} \\
(0.72)\end{array}$ & $\begin{array}{l}-1.59^{\star \star} \\
(0.74)\end{array}$ & $\begin{array}{l}-1.45^{\star \star} \\
(0.68)\end{array}$ \\
\hline (In) Installed base ${ }^{2}$ & $\begin{array}{l}0.10^{\star \star \star} \\
(0.02)\end{array}$ & $\begin{array}{c}0.03 \\
(0.03)\end{array}$ & $\begin{array}{l}0.05^{\star \star} \\
(0.03)\end{array}$ & $\begin{array}{c}0.03 \\
(0.03)\end{array}$ \\
\hline Word processing* Installed base & & & $\begin{array}{c}0.06^{*} \\
(0.03)\end{array}$ & \\
\hline Spreadsheet* Installed base & & & $\begin{array}{l}0.41^{\star \star} \\
(0.19)\end{array}$ & \\
\hline Desktop publishing* Installed bas & & & $\begin{array}{l}-0.44^{\star \star} \\
(0.19)\end{array}$ & \\
\hline $\mathrm{CAD}^{\star}$ Installed base & & & $\begin{array}{l}-0.64^{\star \star \star} \\
(0.18)\end{array}$ & \\
\hline Network intensity*Installed base & & $\begin{array}{l}0.38^{\star \star} \\
(0.16)\end{array}$ & & 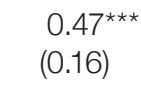 \\
\hline Constant & $\begin{array}{c}23.67^{\star \star \star \star} \\
(4.36)\end{array}$ & $\begin{array}{c}8.89^{*} \\
(5.24)\end{array}$ & $\begin{array}{l}12.73^{* *} \\
(4.93)\end{array}$ & $\begin{array}{c}8.43^{*} \\
(5.00)\end{array}$ \\
\hline$n$ & 125 & 125 & 125 & 125 \\
\hline Model significance (F) & $21.66^{\star * *}$ & $5.51^{\star \star \star}$ & $12.54^{\star \star *}$ & $4.15^{\star \star \star}$ \\
\hline
\end{tabular}

Statistically significant at ${ }^{*} p<0.10,{ }^{* *} p<0.05,{ }^{* \star *} p<0.01$. Standard errors in parentheses.

\section{Discussion}

The primary result of this study is that the influence of installed base size on growth is not homogeneous across competitive contexts, even in high-technology industries which are thought to be characterized by network effects. While there may 
be benefits to network membership for many products and technologies, the extent to which installed base size drives growth may vary significantly across industries and segments. This variation is hypothesized to be dependent upon on the network intensity of a given setting, or the extent to which consumers derive value from network membership for a given product.

Network intensity has several broad implications for innovation management and product diffusion. First, it may explain why we often see variation in the number of product standards across network industries (Eisenmann, 2006). When network intensity is high, we would expect to see a higher prevalence of "winner-take-all" product markets, where an early leader comes to dominate the market. For a product market with lower network intensity, we would expect to see a higher incidence of multiple, evolving standards, as consumers place increased emphasis on product quality and features.

Second, network intensity may inform the firm's optimal entry or generational product release strategy in a given market or segment. When network intensity is high, then extant theory suggests early releases at all costs, thereby quickly building an installed base. As network intensity decreases, competition becomes increasingly focused on quality differentiation between competing products, suggesting that firms should defer releases to improve the intrinsic quality of the product.

Finally, a greater understanding of network intensity may allow for the possibility that firms can manipulate certain aspects of their products to make them more or less network intensive. ${ }^{3}$ For example, an online auction company may try to increase the network-independent value of its product by adding a multi-service Web portal interface. Conversely, online video gaming can be viewed as an attempt to add direct network value to a stand-alone console.

\section{Theoretical Implications}

This research offers several implications for the literature on network effects and strategic management. First, the results are broadly consistent with the idea that first-mover status in a network industry may not always confer a competitive advantage via immediate positive feedback (Lieberman \& Montgomery, 1988; Schilling 2002). Rather, positive feedback from network effects appears to manifest heterogeneously across different competitive settings. As such, effective innovation strategy in network competition appears to depend on the critical trade-off between the pre-emption advantages of early entry, and delays which may improve a product's technical quality and positively impact the growth potential of the firm. 
Second, this work illustrates the complexity of network dynamics. Though there are many direct and indirect benefits resulting from a large installed base, these results indicate that such benefits are not uniform. As such, characterizations of gross installed base size as a distinct competitive advantage by itself may oversimplify the complex nature of network competition in a given industry.

Third, while previous work has postulated asymmetric strength of network effects at the firm level (Shankar \& Bayus, 2003), this is the first study that makes such a contention at the broader segment level. If the influence of network effects varies significantly across competitive contexts, then the ability to accurately gauge the network intensity of a given market or segment becomes a critical firm capability. Inaccurate perceptions of network intensity can have a detrimental impact on performance, as firms may either rush to release low-quality products, or delay releases beyond the point of viability.

\section{Managerial Implications}

The prescriptive contributions of this work are closely aligned with the theoretical advances noted previously. If winning strategies in network industries are more complex than simply establishing an early lead, then the locus of innovative efforts should shift from early product releases to consideration of the trade-offs between releasing new or generational products either too early or too late to maintain a viable competitive position (e.g., Schilling, 1998).

Furthermore, these results offer important implications for both incumbents and new entrants in high-technology markets. Having established that not all network industries exhibit uniform size-on-growth dynamics, the notion of network intensity can facilitate managers in gauging the proportion of value derived from network membership for a given product. As Web-based means of transaction become more prevalent, accurate judgments regarding the network intensity of a given industry or segment will become increasingly important for effective strategy formulation, particularly with regard to new market entry and generational product innovations.

\section{Extensions and Future Research}

Several avenues of potential research flow logically from the results of this work. First, the regression results are consistent with the notion that greatest benefits of network effects may take hold only after a sufficient installed base has been attained. However, this paper does not attempt to address the dynamics of competition in the early stages of a network industry, when leading firms and products have yet 
to be established. The technical quality of products in network industries is often thought to suffer as consumers rush to join the largest network regardless of quality (Besen \& Farrell, 1994; Schilling, 1998; Shapiro \& Varian, 1999). However, if the full benefits of network membership are not evident below some critical mass, then the role of quality in network-based competition - particularly early in the life of network industry - merits further study.

Second, the concept of network intensity has been limited to multiple segments within a single network industry. The extent to which network intensity can be quantified and/or normalized across industries merits further investigation. The establishment of a priori metrics for gauging network intensity would offer a valuable strategic tool for managers in high-technology settings.

Finally, this research was developed under the assumption that network intensity is a largely exogenous aspect of a given market or segment. However, relaxing this assumption may provide valuable insights for strategic management. If firms can partially influence the network intensity of their products, then the manipulation of network intensity is itself a worthy avenue of future study. Using a prior example, large video-game console producers have recently added online capabilities to their core products. Future work in this domain might examine whether this represents a demand-driven evolution of the product-market, or a conscious effort by manufacturers to increase the network intensity of their products.

\section{Limitations and Conclusion}

Several limitations are evident in the course of the study. First, the sample for this study was limited to a single network industry. While network intensity was tested via variation in multiple segments of the industry, a more representative cross-section of high- and low-network intensity industries may prove fruitful for future empirical research. Furthermore, though the time frame of the sample was consciously chosen for its high-growth nature, it would have been ideal to examine the industry from its inception. However, limitations in the availability of data earlier than 1986 made this approach less viable.

Second, the sample has been limited to a setting where one-sided network effects tend to accrue to end users of the product. While technology diffusion and the emergence of dominant designs are integral aspects of product life cycles in many industries (Arthur, 1996; Eisenmann, Parket \& van Alstyne, 2006; Schilling, 1998; Suarez \& Utterback, 1995), this study consciously focuses on one particular type of industry, application software. In this setting, direct and indirect network effects are 
thought to offer distinct value to consumers, and thus uniquely influence patterns of product diffusion. Markets influenced by "two-sided" network effects, involving the interplay of two sets of participants in a given platform (Eisenmann, Parker \& van Alstyne, 2006) may present more complicated strategic scenarios than those addressed here.

Third, this study involves a trade-off between depth and breadth in the sample. While the sample size is smaller than some comparable longitudinal studies of growth, recent studies have made similar concessions with respect to sample size in order to gain a deeper understanding of network dynamics. ${ }^{4}$ Furthermore, the availability of more recent data on network competition in emerging industries such as social media or online auctions, which serve as logical and contemporary examples of network dynamics, might have provided substantial insight into the focal relationships in this study.

Finally, this study is an exploratory step toward understanding the impact of heterogeneity in network effects across industries. As such, simple interaction terms were used to gauge differences in size-on-growth effects across segments of the application software industry. The development of more robust measures of network intensity, which can account for the a priori strength of network effects in a given industry, would benefit scholars and practitioners alike.

In conclusion, this research explores the notion that the influence of network effects varies across competitive settings. The results indicate that the effect of installed base size on growth varies significantly across segments of the application software industry, and in a manner consistent with the network intensity of the segments. Future research should further examine the concept of network effects as a continuum, and the moderating role of network intensity on the effectiveness of strategic actions and innovation initiatives.

\section{End Notes}

1. This residual value can also be conceptualized as the autarky value of the product, or the value of the product assuming no interaction among users (Liebowitz \& Margolis, 1999). For consistency, this article will continue to refer to this as networkindependent value, though the terms are largely interchangeable.

2. Lin and Kulatilaka (2006) characterize asymmetric strength of network effects as the "intensity of network effects." They conceptualize this intensity as the coefficient $(\beta)$ in the equation $v(q)=\beta q$, where q represents the quantity demanded for the good. 
3. Note, however, that this paper characterizes network intensity as an exogenous aspect of the product/segment.

4. For example, Shankar and Bayus (2003) use a sample of only 64 product-months in estimating firm-level network effects.

\section{References}

Arthur, W. B. (1989). Competing technologies, increasing returns, and lock-in by historical events. Economic Journal, 99, 116-131.

Arthur, W. B. (1996). Increasing returns and the new world of business. Harvard Business Review, July-August, 100-109.

Astebro, T. (2002). Noncapital investment costs and the adoption of CAD and CNC in U.S. metalworking industries. RAND Journal of Economics, 33(4), 672-688.

Besen, S., \& Farrell, J. (1994). Choosing how to compete: Strategies and tactics in standardization. Journal of Economic Perspectives, 8(2), 117-131.

Bettis, R., \& Hitt, M. (1995). The new competitive landscape. Strategic Management Journal, 16, 7-19.

Brynjolfsson, E. (1996). Network externalities in microcomputer software: An econometric analysis of the spreadsheet market. Management Science, 42, 167182.

Brynjolffson, E., \& Kemerer, C. (1996). Network externalities in microcomputer software: An econometric analysis of the spreadsheet market. Management Science, 42(12).

Chacko, M., \& Mitchell, W. (1998). Growth incentives to invest in a network-externality environment. Industrial and Corporate Change, 7(4), 731-744.

Clements, M., \& Ohashi, H. (2005). Indirect network effects and the product cycle: Video games in the U.S., 1994-2002. Journal of Industrial Economics, 53(4), 515-542.

Cowan, R. (1990). Nuclear power reactors: A study in technological lock-in. Journal of Economic History, 50(3), 541-567.

David, P. (1985). Clio and the economics of QWERTY. American Economic Review, 75(2), 332-337.

Eisenmann, T. (2006). Platform structure in networked markets. Boston: HBS Publishing.

Eisenmann, T. (2007). Internet companies' growth strategies: determinants of investment intensity and long-term performance. Strategic Management Journal, 27(12), 1183-1204 
Eisenmann, T., Parker, G., \& Van Alstyne, M. (2006). Strategies for two-sided markets. Harvard Business Review, 84(10), 92-101.

Evans, D. (1987). The relationship between firm growth, size, and age: Estimates for 100 manufacturing industries. Journal of Industrial Economics, 35(4), 567-581.

Farrell, J., \& Saloner, G. (1985). Standardization, compatibility, and innovation. RAND Journal of Economics, 16, 70-83.

Farrell, J., \& Saloner, G. (1986). Installed base and compatibility: Innovation, product preannouncements, and predation. American Economic Review, 76(5), 940955.

Fine, C. (1986). Quality improvement and learning in productive systems. Management Science, 32(10), 1301-1315.

Gandal, N. (1994). Hedonic price indexes for spreadsheets and an empirical test for network externalities. RAND Journal of Economics, 25(1), 160-170.

Hall, B. (1987). The relationship between firm size and firm growth in the United States manufacturing sector. Journal of Industrial Economics, 35(4), 583-606.

Hill, C. (1997). Establishing a standard: Competitive strategy and technological standards in winner-take-all industries. Academy of Management Executive, 11(2), 7-18.

Hymer, S., \& Pashigian, P. (1962). Firm size and rate of growth. Journal of Political Economy, 70(6), 556-569.

Katz, M. L., \& Shapiro, C. (1986). Technology adoption in the presence of network externalities. Journal of Political Economy, 94, 822-841.

Katz, M. L., \& Shapiro, C. (1994). Systems competition and network effects. Journal of Economic Perspectives, 8(2), 93-115.

Lin, L., \& Kulatilaka, A. (2006). Network effects and technology licensing with fixed fee, royalty, and hybrid contracts. Journal of Management Information Systems, 23(2), 91-118.

Lieberman, M., \& Montgomery, D. (1988). First-mover advantages. Strategic Management Journal, 9, 41-58.

Liebowitz, S. \& Margolis, S. (1990). The fable of the keys. Journal of Law and Economics, 33, 1-26.

Liebowitz, S., \& Margolis, S. (1999). Winners, losers, and Microsoft. Oakland, CA: The Independent Institute.

Majumdar, S., \& Venkatraman, S. (1998). Network effects and the adoption of new technology: Evidence from the U.S. telecommunications industry. Strategic Management Journal, 19(11), 1045-1062. 
McIntyre, D., \& Subramaniam, M. (2009). Strategy in network industries: A review and research agenda. Journal of Management, 35(6), 1494-1517.

Parker, G., \& Van Alstyne, M. (2005). Two-sided networks: A theory of information product design. Management Science.

Penrose, E. (1955). Limits to the growth and size of firms. American Economic Review, 45(2), 531-543.

Porter, M. (1980). Competitive Strategy. New York: The Free Press.

Rohlfs, J. (1974). A Theory of interdependent demand for a communications service. Bell Journal of Economics and Management Science, 16.

Saloner, G. \& Shepard, A. (1995). Adoption of technologies with network effects: An empirical explanation of the adoption of automated teller machines. RAND Journal of Economics, 26(3), 479-501.

Schilling, M. (1998). Technological lockout: An integrative model of the economic and strategic factors driving technology success and failure. Academy of Management Review, 23(2), 267-284.

Schilling, M. (2002). Technology success and failure in winner-take-all markets: The impact of learning orientation, timing, and network externalities. Academy of Management Journal, 45(2), 387-398.

Shankar, V., \& Bayus, B. (2002). Network effects and competition: An empirical analysis of the home video game industry. Strategic Management Journal, 24, 375-384.

Shapiro, C., \& Varian, H. (1999). Information Rules. Boston: HBS Press.

Stigler, G. (1964). A theory of oligopoly. Journal of Political Economy, February.

Stremersch, S., Tellis, G., Franses, P., \& Binken, J. (2007). Indirect network effects in new product growth. Journal of Marketing, 71(3), 52-74.

Suarez, F. (2005). Network effects revisited: The role of strong ties in technology selection. Academy of Management Journal, 48(4), 710-722.

Tanriverdi, H., \& Lee, C. (2008). Within-industry diversification and firm performance in the presence of network externalities: Evidence from the software industry. Academy of Management Journal, 51(2), 381-397.

Venkatraman, N., \& Lee, C. (2004). Preferential linkage and network evolution: A conceptual model and empirical test in the U.S. video game sector. Academy of Management Journal, 47(6), 876-892. 


\section{Biographical Sketch of Author}

Dr. David P. McIntyre is an Assistant Professor of Management at Providence College. He received his Ph.D. in Business Administration from the University of North Carolina. His current work examines strategy and innovation management in high-technology industries. This research appears in the Journal of Management, the Journal of Product Innovation Management, and the Journal of High Technology Management Research, among other venues. 
